\title{
Consequences of the COVID-19 Pandemic: A Study from India
}

\author{
Madhavachandran $\mathrm{K}^{1 *}$, Naveena $\mathrm{K}^{2}$, Venu Prasad $\mathrm{HD}^{3}$ and Valsan $\mathrm{T}^{4}$ \\ ${ }^{1}$ Social Researcher, Kozhikode, Kerala, India \\ ${ }^{2}$ Statistician, Kozhikode, Kerala, India \\ ${ }^{3}$ Extension Researcher, Kozhikode, Kerala, India \\ ${ }^{4}$ Vice-President, WEDO, Kozhikode, Kerala, India
}

${ }^{\star}$ Corresponding author: Dr. K. Madhavachandran, President, WEDO (NGO), Kozhikode, Kerala, India; Mobile: +91 9446397971; Email: chandmadhava@gmail.com

Received: January 19, 2022; Accepted: January 26, 2022; Published: January 31, 2022

\begin{abstract}
A study was carried out in India considering the consequences, which could have been faced by people due to the first wave of COVID-19 pandemic 2020. Data collected online through questionnaire using the snow ball sampling technique from 400 respondents from 13 States of India was considered. The questionnaire contained total 17 negative and positive items related to the consequences/outcome of the pandemic, which could also psychologically influence people unfavourably and favourably. The responses were scored to work out the total consequences score. The data was analyzed using Factor Analysis and Odds Ratio test and interpreted as proportion and scores. The results of the consequences score show that majority of the respondents have faced medium level of consequences, while some of them faced low consequences only. Negative consequences such as mental stress, income/ job loss, less social interaction, increase in health problems, unrest or quarrel in the family, social interaction/transportation/recreation/capability of old people to support themselves/health care for medical problems being affected, work from home not helpful, and less reduction in family expenses during the pandemic have been observed under the study. Positive consequences of the pandemic such as reduced pollution and better environmental conditions due to lock down, lock down time used for learning agriculture/fisheries, and increase in time spent with family are also evident. Factor analysis shows that age, education, and no. of family members of the respondents explain $69.9 \%$ of the variability in their total consequences score. Odds ratio reveals that people aged more than 40 years, with PG and Degree qualifications, and having more than 4 family members faced less COVID related consequences. This is also substantiated by the comparatively higher proportion of people under these categories of the three characteristics giving favourable responses for positive and negative consequences items under the study.
\end{abstract}

Keywords: COVID-19, Pandemic, Consequences, Consequences score

\section{Introduction}

COVID-19 (Coronavirus Disease 2019) was first identified in China on November 172019 [1]. From there, it spread to other countries very rapidly and hence, WHO declared the disease as pandemic. The first case of COVID-19 reported in India was on $30^{\text {th }}$ January 2020 [2]. The disease mainly spreads through respiratory droplets and the symptoms range from cough, throat infection, fever, body pain to the death of an individual. Older people are considered more prone to COVID-19 owing to their weak immune system [3].

The emergence of COVID-19 came as a shock to the entire world since the disease was spreading rapidly and most of the nations declared lockdown measures to contain the spread of the virus. This resulted in large scale economic disruption as most of the firms shutdown their production and business houses were closed. Many people lost their jobs and experienced difficulties in their lives due to the pandemic.

This study was carried out taking into consideration the consequences, which could have been faced by people due to the COVID-19 pandemic.

\section{Methods and Materials}

The study was conducted during the first wave of COVID-19 pandemic 2020 in India. Data was collected online through questionnaire survey using the snow ball sampling technique. The questionnaire was initially sent to some people through WhatsApp/email, with a request to forward it to more people. Accordingly, responses were obtained from 412 respondents from the States of Kerala, Karnataka, Tamil Nadu, Andhra Pradesh, Telangana, Maharashtra, Gujarat, Haryana, Rajasthan, Odisha, Bihar, West Bengal and UP in India. After removing random and incomplete data, 400 samples were considered for analysis.

The questionnaire contained 17 items related to the consequences/ outcome of the pandemic. Both negative and positive consequences items were considered, which could also psychologically influence people unfavourably and favourably respectively. They were selected based on media reports, review of literature etc. The negative items relate to the direct psychological consequence of the pandemic such as mental stress and those which could indirectly affect people psychologically such as loss of income, job etc. The positive items relate to aspects such as reduced pollution and better environmental conditions due to the lock down, lock down time used for learning agriculture/fisheries etc. 
The five-point continuum to the items on how much the respondents were affected due to the first wave of the pandemic were: Very much, Moderately, Less, Very less, and Not at all. These responses for the negative consequences items were scored from 1 to 5 and reverse scored for the positive items. The total score of all the items was considered as the total COVID consequences score. A higher score indicates less consequences faced by the respondent and vice versa. The level of higher consequences faced due to the pandemic in relation to the bench mark level of "No consequences" faced (as considered in this study) was calculated as follows: The total consequences score of the respondent is subtracted from the maximum possible score of 85 (which will be obtained by a respondent who has faced "No consequences" at all), divided by 85 and expressed in percentage as the level of higher consequences faced in relation to the bench mark level of "No consequences".

The characteristics of the respondents such as sex, age, education, marital status and no. of family members were also included in the questionnaire. Data was analyzed using statistical techniques such as Factor Analysis and Odds ratio test and interpreted as proportion and scores.

\section{Results}

\section{COVID Related Consequences Faced}

Since there are negative as well as positive consequences due to the COVID-19 pandemic analyzed in this study, the terms consequences as well as outcome have been used in Table $1.17 .5 \%$ respondents were of the opinion that the COVID-19 pandemic 2020 has affected their lives very much, while, it affected $42.5 \%$ moderately. $16.5 \%$ and $10.5 \%$ mentioned that it affected them only less and very less respectively, while the pandemic did not affect $13 \%$ respondents at all (Table 1). It can be made out from Table 1 that $27.5 \%$ respondents experienced very much and $45 \%$ moderate mental stress due to the pandemic. The income of $51 \%$ respondents only were found to be affected either very much or moderately due to the pandemic, while, regarding loss of job, $34.5 \%$ report not at all affected, $12 \%$ very less and $23.5 \%$ less affected (Table 1). With respect to health care for existing/new medical problems, only $8 \%$ are very much and $25.5 \%$ moderately affected. Similarly, the respondents affected very much and moderately through increase in health problems is comparatively less than those who report less, very less and not at all affected.

Unrest/quarrel in the family has not at all increased through remaining more at home for $46 \%$ respondents, while $15.5 \%$ and $22 \%$ report very less and less increase in this respectively. $42.5 \%$ and $31 \%$ respectively reported that social interaction was affected very much and moderately due to the pandemic. $59 \%$ and $26 \%$ are of the opinion that freedom of movement has been affected very much and moderately respectively, while almost similar proportion mention that transportation was affected very much and moderately.

$37.5 \%$ and $31 \%$ respondents report that their leisure/recreation activities were affected very much and moderately respectively. A total of $64 \%$ respondents report that the pandemic affected the capability of old persons to support themselves either very much or moderately. Work from home during the pandemic period was less and very less helpful for $51 \%$ respondents, while it did not help $23.5 \%$ respondents at all.

A total of $64 \%$ respondents reports only less or very less reduction in family expenses during the pandemic period.

$63.5 \%$ and $25.5 \%$ respondents are of the opinion that the pandemic induced lock down very much and moderately reduced pollution and created better environmental conditions respectively. Similarly, the lock down time was used for learning agriculture/fisheries \& other

Table 1: Consequences/outcome of the COVID-19 pandemic 2020.

\begin{tabular}{|c|c|c|c|c|c|c|c|}
\hline \multirow{3}{*}{ Sl. No. } & \multirow{3}{*}{ Consequence/outcome of the pandemic } & \multicolumn{5}{|c|}{ Respondents (\%) } & \multirow{3}{*}{ Total (\%) } \\
\hline & & \multicolumn{5}{|c|}{ Extent of consequence/outcome faced } & \\
\hline & & Very much & Moderately & Less & Very less & Not at all & \\
\hline 1 & Mental stress & 27.5 & 45.0 & 13.5 & 5.5 & 8.5 & 100 \\
\hline 2 & Affected income & 20.5 & 30.5 & 17.5 & 11.0 & 20.5 & 100 \\
\hline 3 & Affected due to loss of job & 15.5 & 14.5 & 23.5 & 12.0 & 34.5 & 100 \\
\hline 4 & Affected health care for existing/new medical problems & 8.0 & 25.5 & 23.5 & 20.0 & 23.0 & 100 \\
\hline 5 & By remaining more at home, unrest/quarrel in the family increased & 4.0 & 12.5 & 22.0 & 15.5 & 46.0 & 100 \\
\hline 6 & Social interaction affected & 42.5 & 31.0 & 12.5 & 6.5 & 7.5 & 100 \\
\hline 7 & Affected freedom of movement & 59.0 & 26.0 & 6.0 & 4.5 & 4.5 & 100 \\
\hline 8 & Transportation affected & 55.0 & 27.5 & 9.5 & 2.0 & 6.0 & 100 \\
\hline 9 & Other health problems increased & 2.5 & 17.5 & 24.0 & 20.5 & 35.5 & 100 \\
\hline 10 & Leisure/recreation activities affected & 37.5 & 31.0 & 13.5 & 9.5 & 8.5 & 100 \\
\hline 11 & School closure increased load on parents ${ }^{*}$ & 32.1 & 28.5 & 15.0 & 10.8 & 13.6 & 100 \\
\hline 12 & Affected the capacity of old persons to support themselves ${ }^{* *}$ & 23.3 & 40.7 & 17.4 & 7.6 & 11.0 & 100 \\
\hline 13 & Lock down reduced pollution and created better environmental conditions & 63.5 & 25.5 & 4.5 & 3.5 & 3.0 & 100 \\
\hline 14 & Lock down time was used for learning agriculture/fisheries \& other hobbies & 26.0 & 37.0 & 13.0 & 8.5 & 15.5 & 100 \\
\hline 15 & Time spent with family increased & 55.0 & 28.0 & 7.0 & 3.0 & 7.0 & 100 \\
\hline 16 & Working from home helped me and my family & 13.0 & 12.5 & 19.5 & 31.5 & 23.5 & 100 \\
\hline 17 & Family expenses reduced & 13.5 & 11.5 & 21.5 & 42.5 & 11.0 & 100 \\
\hline
\end{tabular}

${ }^{*}$ Among those who have children.

${ }^{* *}$ Among those having old persons in their house. 
hobbies by a total of $63 \%$ respondents very much and moderately. Time spent with their families increased very much during the pandemic period for $55 \%$ and moderately for $28 \%$ respondents, even though the level of social interaction with other people was restricted very much for $42.5 \%$ and moderately for $31 \%$ respondents.

\section{COVID Consequences Score}

Table 2 shows the total COVID consequences score of the respondents categorised based on the quartile method. A high score indicates that the respondents have faced low consequences and vice versa for a low score. Majority (44.5\%) of the respondents in the study have faced medium COVID related consequences, while $27.5 \%$ faced low consequences only. It may be made out from Table 3 that in the case of $77.5 \%$ respondents, more consequences faced (in relation to the condition of "No consequences faced") is in the range of $57.6 \%$ to $35.3 \%$. More consequences faced is in the lowest range of 34.1 to $14.1 \%$ only for $13.7 \%$ respondents.

Table 2: Categories of total COVID consequences score.

\begin{tabular}{|l|c|c|c|c|}
\hline $\begin{array}{l}\text { Total consequences } \\
\text { score category }\end{array}$ & Mean score & $\begin{array}{c}\text { Minimum } \\
\text { score }\end{array}$ & $\begin{array}{c}\text { Maximum } \\
\text { score }\end{array}$ & Respondents (\%) \\
\hline High $^{* *}$ & 57.14 & 52 & 73 & 27.5 \\
\hline Low $^{* * *}$ & 36.17 & 16 & 41 & 28.0 \\
\hline Medium & 46.26 & 42 & 51 & 44.5 \\
\hline Total & 46.43 & 16 & 73 & 100 \\
\hline
\end{tabular}

${ }^{*}$ Based on quartile method.

${ }^{* *}$ Low consequences faced.

${ }^{* * *}$ High consequences faced.

Table 3: Range of total COVID consequences score.

\begin{tabular}{|l|c|c|}
\hline $\begin{array}{l}\text { Range of total } \\
\text { consequences score }\end{array}$ & $\begin{array}{c}\text { Range (\%) of more } \\
\text { consequences faced }\end{array}$ & Respondents (\%) \\
\hline $16-35$ & $81.2-58.8$ & 8.8 \\
\hline $36-55$ & $57.6-35.3$ & 77.5 \\
\hline $56-73$ & $34.1-14.1$ & 13.7 \\
\hline Total & & 100 \\
\hline
\end{tabular}

an relation to the condition of "No consequences faced".

Lower the score, higher the consequences faced.

Table 4: Factor analysis of total COVID consequences score.

\begin{tabular}{|l|c|c|c|c|}
\hline \multirow{2}{*}{ Characteristics } & \multicolumn{4}{|c|}{ Factor loading } \\
\cline { 2 - 5 } & \multicolumn{4}{|c|}{ Factor } \\
\cline { 2 - 5 } & $\mathbf{1}$ & $\mathbf{2}$ & $\mathbf{3}$ & $\mathbf{4}$ \\
\hline Age & 0.77 & -0.02 & 0.64 & 0.00 \\
\hline Sex & 0.29 & 0.10 & 0.25 & -0.34 \\
\hline Education & -0.31 & 0.90 & 0.30 & 0.00 \\
\hline Marital status & 0.37 & 0.02 & 0.19 & 0.55 \\
\hline No. of family members & -0.69 & -0.44 & 0.58 & 0.00 \\
\hline Family members less10 years of age & -0.32 & -0.10 & 0.11 & 0.30 \\
\hline Marital status & -0.02 & -0.10 & 0.44 & -0.07 \\
\hline Income & -0.03 & 0.39 & 0.21 & 0.15 \\
\hline Initial Eigen values & 1.78 & 1.44 & 1.29 & 1.06 \\
\hline Variance (\%) & 22.36 & 18.11 & 16.12 & 13.32 \\
\hline Cumulative \% & 22.36 & 40.47 & 56.60 & 69.92 \\
\hline
\end{tabular}

\section{Characteristics Contributing to the Consequences Score}

Factor analysis was carried out to determine the major characteristics of the respondents contributing to the total COVID consequences score. The results are presented in Table 4, which shows that the first four factors show significant eigen value $(>1)$ and explain $69.92 \%$ of the variability in the total score of the respondents. Among the characteristics, age, education, and no. of family members contribute significantly (factor loading $>0.50$ ) to the factor components observed in the total consequences score.

\section{Chances to Obtain High Total COVID Consequences Score for People with Different Age, Education and No. of Family Members}

Table 5 shows the results of the statistical test of odds ratio with respect to high total consequences score (less consequences faced) with respect to age, education and no. of family members, which showed high factor loading (Table 4). It can be made out from Table 5 that respondents with more than 4 family members have 0.37 times more chances of obtaining high score (indicting less consequences) than those with less than 4 family members. Similarly, respondents aged more than 40 years have 0.79 times more chances of obtaining high score (indicting less consequences) than those aged less than 40 . However, $\mathrm{PhD}$ holders have 0.33 times less chances of obtaining high score (indicting less consequences) than those who have PG and Degree.

Considering 13.7\% respondents shown in Table 3 who have the highest range of total score of 56 to 73 (which implies that only $34.1 \%$ to $14.1 \%$ more consequences have been faced by them than the condition of "No consequences faced"), $63.6 \%$ of these respondents are found to have a total score of 60 and above. Total consequence score of 60 and above implies that the higher consequences faced by them in relation to the condition of "No consequences faced" is $29.4 \%$ and less only.

Hence, based on the results of factor analysis (Table 4) and odds ratio (Table 5), the proportion of respondents under different categories of age, education and no. of family members (the characteristics considered in working out the odds ratio) was worked out for those getting a total consequence score of 60 and above. The results are shown in Table 6 .

Table 5: Odds ratios of personal characteristics on total COVID consequences score.

\begin{tabular}{|l|c|c|}
\hline Characteristic & Category & Odds ratio $^{*}$ \\
\hline Age & $>40$ vs. $<40$ & 1.79 \\
\hline No. of family members & $>4$ vs. $<4$ & 1.37 \\
\hline Education & PhD vs PG and Degree & 0.67 \\
\hline
\end{tabular}

"Indicating the chances of respondents to have a high total score (less consequences faced).

Table 6: Age, Number of family and education of respondents having high total COVID consequences score.

\begin{tabular}{|l|c|c|c|c|c|}
\hline \multicolumn{2}{|c|}{ Respondents (\%) with total consequences score of 60 and above } \\
\hline Age & \multicolumn{2}{|c|}{ No. of family members } & \multicolumn{2}{c|}{ Education } \\
\hline Up to 40 & $>40$ & Up to 4 & $>4$ & PhD & PG and Degree \\
\hline 26.0 & 74.0 & 40.7 & 59.3 & 26.0 & 74.0 \\
\hline
\end{tabular}

The maximum total score of respondents in the study was 73 . 
It can be made out from Table 6 that while $74 \%$ respondents aged more than 40 years have total consequences score of 60 and above, only $26 \%$ below 40 years of age have this score. This could be the reason for the odds ratio of 1.79 for age (Table 5), which implies that respondents aged more than 40 years have $79 \%$ more chance of obtaining high score (less consequences) than those aged less than 40 .

Similarly, while $59.3 \%$ of respondents with more than 4 family members get a total consequence score of of 60 and above, the figure is only $40.7 \%$ for those with less than 4 members (Table 6). This could be why the odds ratio of 1.37 is there for no. of family members (Table 5), indicating that respondents with more than 4 family members have $37 \%$ more chance of obtaining high score (less consequences) than those with less than 4 family members.

However, with regard to education, while $74 \%$ respondents with PG and Degree have total consequences score of 60 and above, only $26 \%$ with $\mathrm{PhD}$ are having this score. The odds ratio was 0.67 for education (Table 5), which means that $\mathrm{PhD}$ holders have $33 \%$ less chance of obtaining high score (less consequences) than those with PG and Degree qualifications.
For better interpretation of the influence of age, education and no. of family members (family size) on the total COVID consequences score (whose results were observed in the odds ratio test), the variation in proportion of responses to different consequences items were worked out for these characteristics. Only perceptible differences in the responses to the consequences items between various categories of the characteristics have been included in the concerned tables which follow.

Age wise responses to different consequences items are shown in Table 7. With respect to the negative consequence item, namely, income affected due to the COVID-19 pandemic, while $31.7 \%$ respondents up to 40 years of were very much affected, only $10.5 \%$ of those with more than 40 years of age report in this manner. Further, $27 \%$ of those aged more than 40 reports that income was not at all affected due to the occurrence of the pandemic, when compared to only $12.3 \%$ of those less than 40 years of age (Table 7). While $19 \%$ of respondents up to the age of 40 were affected very much due to loss of job, the figure for more than 40 age respondents is only $6 \% .19 .5 \%$ of respondents with age more than 40 were less affected due to job loss, while only $15.5 \%$ of people up to 40 years of age report in this manner (Table 7).

Table 7: Age wise responses to consequences items

\begin{tabular}{|c|c|c|c|c|c|c|c|}
\hline & & & Very much & Moderately & Less & Very less & Not at all \\
\hline \multirow{2}{*}{1} & \multirow{2}{*}{ Income affected } & Up to 40 & 31.7 & $\mathrm{NA}^{*}$ & NA & NA & 12.3 \\
\hline & & $>40$ & 10.5 & NA & NA & NA & 27.0 \\
\hline \multirow{2}{*}{2} & \multirow{2}{*}{ Job loss } & Up to 40 & 19.0 & NA & 15.5 & NA & NA \\
\hline & & $>40$ & 6.0 & NA & 19.5 & NA & NA \\
\hline \multirow{2}{*}{3} & \multirow{2}{*}{ Time spent with the family increased } & Up to 40 & NA & NA & 7.8 & NA & 7.2 \\
\hline & & $>40$ & NA & NA & 4.8 & NA & 5.4 \\
\hline \multirow{2}{*}{4} & \multirow{2}{*}{ Due to lockdown, quarrel/unrest in the family increased } & Up to 40 & 6.1 & 17.8 & NA & NA & 34.0 \\
\hline & & $>40$ & 2.5 & 7.6 & NA & NA & 51.2 \\
\hline \multirow{2}{*}{5} & \multirow{2}{*}{ Affected freedom of movement } & Up to 40 & 61.1 & NA & NA & 3.9 & 3.9 \\
\hline & & $>40$ & 56.7 & NA & NA & 5.4 & 7.4 \\
\hline \multirow{2}{*}{6} & \multirow{2}{*}{ Transportation affected } & Up to 40 & 62.8 & NA & 8.3 & 0.6 & NA \\
\hline & & $>40$ & 48.0 & NA & 10.4 & 3.7 & NA \\
\hline \multirow{2}{*}{7} & \multirow{2}{*}{ Stress level including fear of virus infection increased } & Up to 40 & 34.4 & NA & NA & NA & 7.8 \\
\hline & & $>40$ & 18.8 & NA & NA & NA & 12.8 \\
\hline \multirow{2}{*}{8} & \multirow{2}{*}{ Other diseases/health problems increased } & Up to 40 & NA & 21.7 & NA & 18.3 & 26.7 \\
\hline & & $>40$ & NA & 14.4 & NA & 20.9 & 37.2 \\
\hline \multirow{2}{*}{9} & \multirow{2}{*}{ Health care for existing/new medical problems increased } & Up to 40 & 11.1 & NA & 18.9 & 15.7 & NA \\
\hline & & $>40$ & 6.0 & NA & 21.3 & 18.4 & NA \\
\hline \multirow[b]{2}{*}{10} & \multirow[b]{2}{*}{ Leisure/recreation activities affected } & Up to 40 & 37.8 & NA & NA & 7.2 & 11.6 \\
\hline & & $>40$ & 34.2 & NA & NA & 9.5 & 13.8 \\
\hline \multirow{2}{*}{11} & \multirow{2}{*}{ School closure increased pressure/load in children and parents } & Up to 40 & 33.9 & 25.0 & 7.8 & 6.1 & NA \\
\hline & & $>40$ & 11.0 & 14.9 & 12.6 & 12.6 & NA \\
\hline \multirow{2}{*}{12} & \multirow{2}{*}{ Affected the capacity of older people to support themselves } & Up to 40 & 26.2 & NA & 14.4 & 3.3 & 7.2 \\
\hline & & $>40$ & 13.8 & NA & 16.3 & 9.1 & 12.9 \\
\hline \multirow{2}{*}{13} & \multirow{2}{*}{ Lockdown time was used in learning/doing agriculture/fisheries etc. } & Up to 40 & NA & 31.1 & 16.2 & NA & NA \\
\hline & & $>40$ & NA & 41.6 & 10.1 & NA & NA \\
\hline
\end{tabular}

${ }^{*}$ Data not shown since perceptible difference was not observed in these responses for the consequences items. 
Now, considering a positive consequence item -time spent with family increased during the pandemic period, Table 7 shows that while a higher proportion (7.8\%) respondents under the age group of more than 40 report as less time spent with the family, only $4.8 \%$ respondents with more than 40 age report so. Further, while $7.2 \%$ of up to 40 age report as not all spent time with the family, only $5.4 \%$ of people aged more than 40 report in this manner.

Similarly, considering the other consequences items shown in Table 7, it can be inferred that a comparatively lower proportion of respondents above the age of 40 report affected very much/moderately for the negative consequences items than those with up to 40 years of age, while a higher proportion of respondents above the age of 40 report affected less/very less/not at all for the negative consequences items, when compared to the respondents aged up to 40 years. Similarly, with regard to the positive consequences items shown in Table 7, a comparatively higher proportion of respondents above the age of 40 report as experiencing very much/moderately for the positive consequences items than those with up to 40 years of age, while a lower proportion of respondents above the age of 40 report as less/very less/not at all for the positive items, when compared to respondents aged up to 40 years.

These trends indicate that people with more than 40 years of age have faced comparatively less consequences than those aged less than
40 years. This would also help to substantiate the results of the odds ratio of 1.79 for age of the respondents (Table 5), which implies that respondents in the study who are aged more than 40 years have $79 \%$ more chance of obtaining a high score/facing less consequences) than those aged less than 40 .

As in the case of age, it can be inferred from the data presented in Table 8 that a comparatively lower proportion of respondents with PG and Degree qualification report affected very much/moderately for the negative consequences items than those having $\mathrm{PhD}$, while a higher proportion of respondents with PG and Degree report as affected less/ very less/not at all for the negative consequences items, when compared to those having $\mathrm{PhD}$. Similarly, with regard to the positive consequences items, a comparatively higher proportion of respondents with PG and Degree report as experiencing very much/moderately for the positive consequences items than those with $\mathrm{PhD}$, and a lower proportion of $\mathrm{PG}$ and Degree respondents report less/very less/not at all for the positive items, when compared to respondents having $\mathrm{PhD}$ qualification.

These findings indicate that people with PG and Degree qualifications have faced comparatively less consequences than those having $\mathrm{PhD}$, which would also support the result of odds ratio of 0.67 for Education (Table 5), which implies that $\mathrm{PhD}$ holders have $33 \%$ less chance of obtaining high score/facing less consequences than those with PG and Degree qualifications.

Table 8: Education wise responses to consequences items.

\begin{tabular}{|c|c|c|c|c|c|c|c|}
\hline \multirow{2}{*}{ Sl. No. } & \multirow{2}{*}{ Consequence item } & \multirow{2}{*}{ Education } & \multicolumn{5}{|c|}{ Respondents (\%) reporting } \\
\hline & & & Very much & Moderately & Less & Very less & Not at all \\
\hline \multirow{2}{*}{1} & \multirow{2}{*}{ Income affected } & PG and Degree & NA & 28.0 & $\mathrm{NA}^{*}$ & NA & 21.4 \\
\hline & & $\mathrm{PhD}$ & NA & 36.2 & NA & NA & 16.2 \\
\hline \multirow{2}{*}{2} & \multirow{2}{*}{ Loss of job } & PG and Degree & NA & NA & 19.4 & NA & 28.2 \\
\hline & & $\mathrm{PhD}$ & NA & NA & 15.0 & NA & 23.7 \\
\hline \multirow{2}{*}{4} & \multirow{2}{*}{ Due to lockdown, quarrel/unrest in the family increased } & PG and Degree & NA & 12.9 & NA & 13.6 & 44.4 \\
\hline & & $\mathrm{PhD}$ & NA & 15.0 & NA & 10.0 & 32.5 \\
\hline \multirow{2}{*}{5} & \multirow{2}{*}{ Social interaction and cohesion affected } & PG and Degree & NA & 27.8 & 12.3 & 7.3 & NA \\
\hline & & $\mathrm{PhD}$ & NA & 40.0 & 8.8 & 2.5 & NA \\
\hline \multirow{2}{*}{6} & \multirow{2}{*}{ Affected freedom of movement } & PG and Degree & 57.0 & NA & NA & NA & 5.4 \\
\hline & & $\mathrm{PhD}$ & 60.0 & NA & NA & NA & 2.5 \\
\hline \multirow{2}{*}{7} & \multirow{2}{*}{ Transportation affected } & PG and Degree & 51.0 & NA & 9.7 & NA & 7.4 \\
\hline & & $\mathrm{PhD}$ & 62.4 & NA & 8.8 & NA & 3.8 \\
\hline \multirow{2}{*}{8} & \multirow{2}{*}{ Stress level including fear of virus infection increased } & PG and Degree & NA & 43.4 & 14.4 & 6.0 & 10.0 \\
\hline & & $\mathrm{PhD}$ & NA & 57.4 & 8.8 & 3.8 & 7.5 \\
\hline \multirow{2}{*}{9} & \multirow{2}{*}{ Other diseases/health problems increased } & PG and Degree & NA & 15.7 & NA & 33.7 & 4.4 \\
\hline & & $\mathrm{PhD}$ & NA & 25.0 & NA & 27.5 & Nil \\
\hline \multirow{2}{*}{10} & \multirow{2}{*}{ Health care for existing/new medical problems increased } & PG and Degree & NA & 15.7 & NA & 23.0 & 33.7 \\
\hline & & $\mathrm{PhD}$ & NA & 25.0 & NA & 11.3 & 27.5 \\
\hline \multirow{2}{*}{11} & \multirow{2}{*}{$\begin{array}{l}\text { School closure increased pressure/load in children and } \\
\text { parents }\end{array}$} & PG and Degree & 20.2 & NA & NA & 8.7 & NA \\
\hline & & $\mathrm{PhD}$ & 25.0 & NA & NA & 5.0 & NA \\
\hline \multirow{2}{*}{12} & \multirow{2}{*}{ Affected the capacity of older people to support themselves } & PG and Degree & NA & 35.1 & NA & 11.0 & NA \\
\hline & & $\mathrm{PhD}$ & NA & 37.5 & NA & 7.5 & NA \\
\hline
\end{tabular}

*Data not shown since perceptible difference was not observed in these responses for the consequences items. 
It can be made out from Table 9 that comparatively less proportion of respondents having more than 4 family members report affected very much/moderately for the negative consequences items than those with a family size of 4 members, while a higher proportion of respondents with family size of more than 4 members report affected less/very less/not at all for the negative consequences items than the respondents with a family size of 4 members. Similarly, for the positive consequences items, comparatively high proportion of respondents with more than 4 family members report experiencing the positive consequences items very much/moderately than those with only 4 members, and a lesser proportion with more than 4 family members report less/very less/not at all for the positive items, when compared to respondents with a family size of 4 .

Similar to age and education, these results substantiate the odds ratio of 1.37 for the characteristic, namely, no. of family members (family size), which indicates $37 \%$ more chance for respondents with a family size of more than 4 members to get a high COVID consequences score/face less consequence than those having a family size of less than 4 .

\section{Discussion}

The study shows that a high proportion of respondents representing various States of India experienced very much and moderate mental stress due to the pandemic. WHO has warned of a "massive increase in mental health conditions" arising from the pandemic. Mental health experts in Mumbai have observed an increase in feelings of anger, frustration and helplessness. [4]. However, in a study conducted in Kerala State of India by WEDO (NGO), majority of the respondents did not experience high level of negative feelings/mental state on the COVID pandemic, while most of them experienced the positive feelings well [5].

A survey found that $77 \%$ of economically active adults in India had lost income due to the pandemic (https://www.hindustantimes. com/india-news/77-indian-adults-lost-income-due-to-covid19-pandemic-survey/story-QjCVwkt4xNmJwcHw4I5wMP.html- retrieved 22 Aug 2021). According to WHO, the COVID-19 pandemic has decimated jobs and many are without the means to earn an income and the access to quality health care during the pandemic induced lockdown (Source: Impact of COVID-19 on people's livelihoods, their health and our food systems-Joint statement by ILO, FAO, IFAD and WHO. October 2020. https://www.who.int/news/ item/13-10-2020-impact-of-covid-19-on-people's-livelihoods-theirhealth-and-our-food-systems-retrieved 22nd August 2021)). Health is defined by WHO as the "state of complete physical, mental and social well-being and not merely the absence of disease or infirmity" (World Health Organization (WHO). Naming the coronavirus disease (COVID19) and the virus that causes it. https://www. who.int/emergencies/diseases/novelcoronavirus-2019/technicalguidance/naming-the-coronavirus-disease-(covid2019)-and-thevirus-that-causes-it. - retrieved $1^{\text {st }}$ November 2021). However, in the present study, income of about $50 \%$ of the respondents only were found to be affected either very much or moderately due to the pandemic, while $70 \%$ respondents mention as not at all affected, very less and less affected with respect to job. Health care for existing/new medical problems are very much and moderately affected on account of the pandemic for some respondents only. Similarly, those who are affected very much and moderately through increase in health problems is comparatively less than the total proportion reporting less, very less and not at all affected.

Not only is the infection with COVID-19 disease a risk, but people are limiting their social interactions with others, working from home, and avoiding unnecessary gatherings. In this study also, social interaction was affected very much and moderately due to the pandemic for a very high proportion of respondents.

While overcoming the COVID-19 pandemic relies on an efficient strategy that involves the whole population, the elderly people are disproportionately affected by this disease [6]. In this study also a good proportion mention that the pandemic affected the capability of old persons to support themselves either very much or moderately.

Table 9: Family size wise responses to consequences items.

\begin{tabular}{|c|c|c|c|c|c|c|c|}
\hline \multirow{2}{*}{ Sl. No. } & \multirow{2}{*}{ Consequence item } & \multirow{2}{*}{$\begin{array}{l}\text { No. of family } \\
\text { members }\end{array}$} & \multicolumn{5}{|c|}{ Respondents (\%) reporting } \\
\hline & & & Very much & Moderately & Less & Very less & Not at all \\
\hline \multirow{2}{*}{1} & \multirow{2}{*}{ Work from home helped me/my family } & Up to 4 & 7.9 & 30.9 & NA & NA & NA \\
\hline & & $>4$ & 11.1 & 45.3 & NA & NA & NA \\
\hline \multirow{2}{*}{2} & \multirow{2}{*}{ Social interaction and cohesion affected } & Up to 4 & NA & 43.2 & 9.6 & 5.3 & 4.7 \\
\hline & & $>4$ & NA & 18.7 & 17.9 & 9.3 & 13.4 \\
\hline \multirow{2}{*}{3} & \multirow{2}{*}{ Affected freedom of movement } & Up to 4 & NA & 38.0 & 6.1 & 2.1 & 1.2 \\
\hline & & $>4$ & NA & 19.3 & 9.5 & 10.6 & 8.4 \\
\hline \multirow{2}{*}{4} & \multirow{2}{*}{$\begin{array}{l}\text { Affected the capacity of older people to } \\
\text { support themselves }\end{array}$} & Up to 4 & NA & 36.6 & 14.3 & 4.7 & NA \\
\hline & & $>4$ & NA & 25.6 & 22.6 & 14.0 & NA \\
\hline \multirow{2}{*}{5} & \multirow{2}{*}{$\begin{array}{l}\text { Lockdown reduced pollution and created } \\
\text { better environmental conditions }\end{array}$} & Up to 4 & 52.2 & NA & 11.0 & NA & NA \\
\hline & & $>4$ & 74.9 & NA & 1.2 & NA & NA \\
\hline \multirow{2}{*}{6} & \multirow{2}{*}{$\begin{array}{l}\text { Lockdown time was used in learning/doing } \\
\text { agriculture/fisheries etc. }\end{array}$} & Up to 4 & 24.9 & NA & NA & 14.6 & 11.5 \\
\hline & & $>4$ & 38.4 & NA & NA & 4.5 & 5.9 \\
\hline
\end{tabular}

${ }^{*}$ Data not shown since perceptible difference was not observed in these responses for the consequences items 
The advantages of working from home include reduced commuting time, avoiding office politics, using less office space, increased motivation, improved gender diversity (e.g. women and careers), healthier workforces with less absenteeism and turnover, higher talent retention, job satisfaction, and better productivity $[7,8]$. However, the present study has shown that work from home during the pandemic period was not at all, very less and less helpful for a very high proportion of people.

Slowdown in spending by Indian households is reported to have saved additional $\$ 200$ billion during Covid pandemic and lockdowns. (https://economictimes.indiatimes.com/news/ economy/indicators/indians-saved-additional-200-billionduring-covid-pandemic-and-lockdowns/articleshow/80386426. cms?utm_source $=$ contentofinterest\&utm_medium $=$ text\&utm campaign=cppst- retrieved $24^{\text {th }}$ August 2021). However, in the present study, high proportion of respondents representing various States of India reported only less or very less reduction in family expenses during the pandemic period.

The study has also shown some positive outcomes during the pandemic period. Very high proportion of respondents report that the COVID 19 induced lock down reduced pollution and created better environmental conditions very much and moderately. Similarly, the lock down time was used for learning agriculture/fisheries and other hobbies very much and moderately by a high proportion of respondents. Even though the level of social interaction outside the family was significantly restricted, time spent with their families increased very much and moderately during the pandemic period for many respondents. Unlike the past, the onset of the COVID pandemic and the resultant lockdown has given families across India and the world a new lease of familial bonding that was otherwise hard to come by. For the first time in a long time, many parents and kids and even grandparents are all under the same roof round-the-clock. This enforced togetherness can deepen relationships for years to come. According to Brad Wilcox, a professor of sociology and director of the National Marriage Project at the University of Virginia, people and families when faced with a global crisis, and especially one of this scale, tend to respond by orienting themselves in a less self-centred way and in a more family-centric way (https://timesofindia.indiatimes.com/life-style/spotlight/how-thelockdown-is-cementing-relationships-and-bringing-families-together/ articleshow/75731732.cms- retrieved $23^{\text {rd }}$ August 2021).

The results reveal that majority of the respondents have faced medium to low COVID related consequences only. Further, people aged more than 40 years, with PG and Degree qualifications, and having more than 4 family members have faced less COVID related consequences only. This is substantiated by the comparatively higher proportion of people under these categories of age, education and no. of family members giving favourable responses for positive and negative consequences items. These findings also support the odds ratio values observed for these categories of the characteristics, which indicate the chances for people falling under the particular categories to face less COVID consequences.

To conclude, majority of the respondents under the study have faced medium level of COVID-19 related consequences, while some of them faced low consequences only. Negative consequences include mental stress, income/job loss, less social interaction, increase in health problems, unrest or quarrel in the family, social interaction/transportation/recreation/capability of old people to support themselves/health care for medical problems being affected, work from home not helpful, and less reduction in family expenses during the pandemic. Positive consequences of the pandemic such as reduced pollution and better environmental conditions due to lock down, lock down time used for learning agriculture/fisheries, and increase in time spent with family are also observed in the study. Age, education, and no. of family members of the respondents explain $69.9 \%$ of the variability in their total consequences score. People aged more than 40 years, those with PG and Degree qualifications, and people having more than 4 family members are found to have faced less consequences only. This is also substantiated by the comparatively higher proportion of people under these categories of age, education and no. of family members giving favourable responses for positive and negative consequences items under the study.

It would be worthwhile if studies on the consequences of the COVID-19 pandemic occurring during different periods are carried out in various parts of the affected countries in order to facilitate the health and other field level workers to introduce location specific measures/strategies to address the problems faced by people. The development of useful information through such studies appears to be essential in the days to come for the policy makers also, keeping in mind the fact that the pandemic is continuing in time, space and severity in different parts of the world even now.

\section{References}

1. Balkhi F, Nasir A, Zehra A, Riaz R (2020) Psychological and behavioral response to the coronavirus (COVID-19) pandemic. Cureus. 12: 5. [crossref]

2. Annamuthu P, Shenbagavadivu, T, Arthi S (2020) A study on the perception and precautionary measures taken by the general public amidst COVID-19. Int J Modern Trends Sci Technol 6: 169-74.

3. Mikaberidze A (2020) Letter To the Editor: "Letter to the Editor." International Journal of Phytoremediation 20: 135-136.

4. Fuad Bakioğlu, Ozan Korkmaz, Hülya Ercan (2020) Fear of COVID-19 and Positivity: Mediating Role of Intolerance of Uncertainty,Depression, Anxiety, and Stress. Int J Ment Health Addict. 28: 1-14.[crossref]

5. Madhava Chandran K, Naveena K, Valsan T, Sreevallabhan S (2021). Analysis of the Mental State of People on COVID-19 Pandemic. International Journal of Indian Psychology 9: 839-845.

6. Daoust J-F (2020) Elderly people and responses to COVID-19 in 27 Countries. PLOSONE. [crossref]

7. Mello JA (2007) Managing Telework Programs Effectively. Employee Responsibilities and Rights Journal 19: 247-261

8. Robertson MM, Maynard WS, McDevitt JR (2003) Telecommuting: Managing the Safety of Workers in Home Office Environments. Professional Safety 48: 30-36.

\section{Citation:}

Madhavachandran K, Naveena K, Venu Prasad HD, Valsan T (2022) Consequences of the COVID-19 Pandemic: A Study from India. Psychol J Res Open Volume 4(1): 1-7. 